\title{
Building Cancer Control Capacity: a Mixed-Method Evaluation of the Research to Reality (R2R) Mentorship Program
}

Michael Sanchez, MPH, CHES; E. Peyton Purcell, MPH, CPH; Joan S. Michie, PhD; Sophia P. Tsakraklides, PhD; Madeline La Porta, MS; Cynthia Vinson, PhD, MPA

Suggested citation for this article: Sanchez M, Purcell EP, Michie JS, Tsakraklides SP, La Porta M, Vinson C. Building Cancer Control Capacity: a Mixed-Method Evaluation of the Research to Reality (R2R) Mentorship Program. Prev Chronic Dis 2014;11:130275. DOI: http://dx.doi.org/10.5888/pcd11.130275国.

PEER REVIEWED

\begin{abstract}
In 2011, the National Cancer Institute launched the Research to Reality (R2R) Pilot Mentorship Program to enhance mentees' core evidence-based public health (EBPH) competencies. In this article, we describe the program and its evaluation results and the program's ability to improve participants' EBPH competencies and appropriateness of program components. Program evaluation consisted of a pre/post program competency questionnaire and interviews with mentees, mentors, mentees' supervisors, and program staff. Mentees reported the same or higher rating in every competency at end of the program, with average increase of 0.6 points on a 4-point scale; the greatest improvements were seen in policy development/program planning. Mentorship programs are a promising strategy to develop EBPH competencies, provide guidance, and disseminate and adapt evidence-based interventions within real-world context.
\end{abstract}

\section{Introduction}

Significant advancements have been made in understanding, preventing, and treating cancer (1). However, evidencebased interventions (EBIs) are not fully integrated into routine practice (2). Common challenges include limited time to gather evidence, lack of skilled personnel, limited access to data, inadequate funding, and differing perspectives of what constitutes "evidence-based" $(3,4)$.

Mentorship programs have been effective in disseminating EBIs in medicine $(5,6)$ and have had some success in public health $(7,8)$. In 2011, the National Cancer Institute (NCI) launched the Research to Reality (R2R) Pilot Mentorship Program (the Program) to enhance mentees' core evidence-based public health (EBPH) competencies $(9,10)$ through 3 primary program components: 1) mentorship and mentee projects, 2) training and support, and 3) online community platform (Figure). A complete description of the Program is available elsewhere (10). 


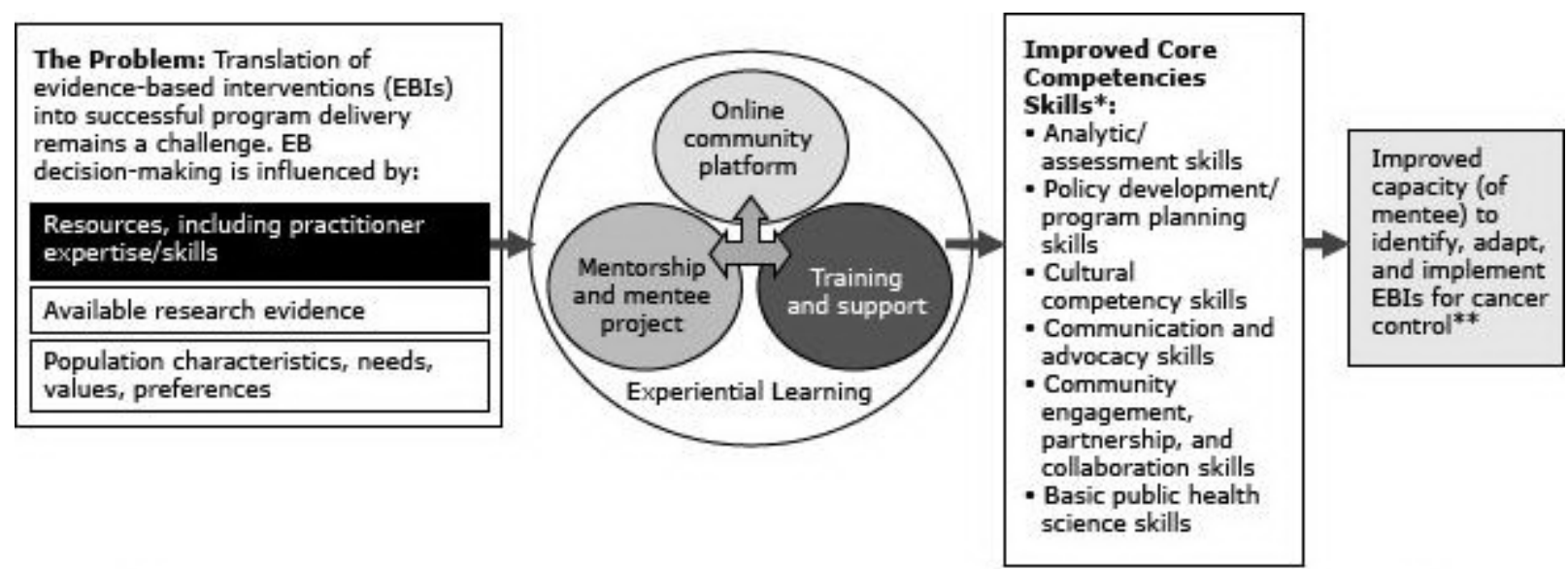

External Factors

Community, clinical, organizational context (ie, work parameters, threats to external validity, leadership)

\footnotetext{
* Mentees will select at least 2 core competencies to focus on during the mentorship program

** Assumptions: Organizational support and resources for EBIs
}

Figure. Research to Reality Pilot Mentorship Program logic model, National Cancer Institute, 2011. Source: Purcell et al (10). [A text description of this figure is also available.]

The purpose of this article is to 1) describe the Program and report evaluation results and 2) discuss the Program's ability to improve participants' EBPH competencies $(9,11)$ and the appropriateness of program components.

\section{Methods}

In May 2011, NCI issued a call for mentee applications through the R2R website, listserv announcements, and relevant newsletters. Applicant eligibility included 1) full-time employment with an organization that addressed cancer control and prevention, 2) supervisor support to participate, 3) at least a master's level public health training or 2 to 3 years equivalent training or experience, and 4) experience working with community organizations. Applicants were required to propose a project that was relevant to their current work and that addressed a comprehensive cancer control plan goal. NCI staff scored applications from 1 (noncompetitive) to 7 (excellent) on factors related to appropriateness of the applicant's training, experience, and feasibility of project in the context of the Program. NCI interviewed the top 8 mentee candidates then selected and matched 6 mentees with mentors.

The evaluation included a preprogram and postprogram competency questionnaire, which assessed changes in EBPH competencies. Mentees rated their skills on a 4-point Likert scale ( $1=$ no ability, 4 = expert) across 6 competency areas: 1) analytic/assessment; 2) policy development/program planning; 3) cultural competency; 4) basic public health science; 5) partnership, collaboration, and community engagement; and 6) advocacy and communication.

Additionally, postprogram individual interviews were conducted with mentees, mentors, mentees' supervisors, and Program staff.

Participation and satisfaction data for trainings, webinars, mentor-mentee activities, Web analytics, and mentees' project deliverables were also reviewed. Because of the small number of participants, most data were qualitative. Mentees rated their preprogram and postprogram EBPH competency level, and changes in ratings were averaged across all mentees. Data for interviews and project deliverables were analyzed through content analysis; coding categories were directly derived from the text data. The codes of the 2 analysts were checked for reliability and consistency. The institutional review board at Westat conducted and approved the evaluation.

\section{Results}

Mentees entered the Program from different organizations, level of experience, topic interests, and competency development needs (Table 1). The EBPH competency areas selected most frequently by mentees were analytic/assessment; partnership, collaboration, and community engagement; and advocacy and communication skills, each of which was chosen by two-thirds of the mentees (Table 2).

For every skill assessed, mentees gave themselves the same or a higher rating at the end of the Program; the greatest change was seen in policy development/program planning (average 1.o increase on a 4-point scale). 
Analytic/assessment skills and partnership, collaboration, and community engagement showed average increases of 0.8 points (Table 2 ).

All Program components were implemented and well-received by participants. Interviews showed that strong administrative support helped participants maintain focus but also provided some flexibility regarding timelines and deliverables that helped with addressing challenges mentees encountered in planning and conducting their projects. Except for the website, the Program's main platform, all other Program components were valued by most of the participants. Although participants praised the website's functionality, they made limited use of it, with lack of time frequently mentioned as a primary cause for underuse. Components mentioned by 2 or more mentees were their mentee-mentor relationship, cohort relationship, trainings, and projects. Mentors valued most the interactions among participants, especially the mentee-mentor pairs, and communication and webinars. Several mentors also mentioned the site visit, project, and trainings. Additionally, all mentees considered the training webinars to be helpful and effective, and all mentees and mentors thought programmatic support was adequate.

Mentees reported improved skills and knowledge in project management, building partnerships, navigating politics, adapting EBIs and watching for fidelity, assessment and analytical skills, manuscript writing, and making presentations. All of these accomplishments occurred despite challenges, such as workplace and life changes and loss of project funding.

\section{Discussion}

To our knowledge, there are no published studies evaluating mentorship programs as a strategy to improve competencies needed to integrate EBIs into public health practice. This evaluation was intended to describe the Program's ability to improve participants' EBPH competencies and the appropriateness of Program components designed to build capacity of cancer control practitioners to navigate "real world" context.

Our evaluation resulted in 3 noteworthy findings. First, all Program components were implemented, and most were valued by participants, including the mentor-mentee relationship, training webinars, and site visit. Second, mentees were able to negotiate the "real world" context that affects the conduct of EBIs, including project management, building partnerships, navigating politics, and adapting EBIs despite multiple challenges encountered. However, this growth did not extend to mentees' organizations. Additional efforts to disseminate mentees' lessons learned in their organizations should be explored. Finally, mentees reported the same or a higher rating for every EBPH competency assessed at the end of the Program, with an average increase of 0.63 points on a 4-point scale.

Although our evaluation was limited in size, the diversity of participants and their related projects indicates that a mentorship program is a feasible strategy across multiple settings, trainings, and contexts. A strength of our pilot program was its ability to remotely integrate evidence-based resources, interactive Web tools and trainings, and mentorship to assist cancer control practitioners with adapting and implementing EBIs to local context. Another strength was the use of multiple data sources and triangulation, which strengthened the evaluation findings.

Our findings show that mentorship programs have great promise as an effective means to develop EBPH competencies for cancer control practitioners and provide guidance and technical assistance with adapting EBIs to "real world" local settings. Further research is warranted to replicate these results on a larger scale and in comparison with other strategies.

\section{Acknowledgments}

This project was funded in whole or in part with federal funds from the NCI, National Institutes of Health, under contract no. HHSN261200800001E. The content of this publication does not necessarily reflect the views or policies of the Department of Health and Human Services, nor does mention of trade names, commercial products, or organizations imply endorsement by the US government.

\section{Author Information}

Corresponding Author: Michael Sanchez, MPH, CHES, National Cancer Institute, 9609 Medical Center Dr, Rockville, MD 20850. Telephone: 240-276-6884. E-mail: sanchezgarciama@mail.nih.gov.

Author Affiliations: E. Peyton Purcell, Clinical Research Directorate/CMRP, SAIC-Frederick, Inc, Frederick National Laboratory for Cancer Research, Frederick, Maryland; Joan S. Michie, Sophia P. Tsakraklides, Westat, Rockville, Maryland; Madeline La Porta, MS1; Cynthia Vinson, National Cancer Institute, Rockville, Maryland.

\section{References}


1. Edwards BK, Ward E, Kohler BA, Eheman C, Zauber AG, Anderson RN, et al. Annual report to the nation on the status of cancer, 1975-2006, featuring colorectal cancer trends and impact of interventions (risk factors, screening, and treatment) to reduce future rates. Cancer 2010;116(3):544-73. CrossRef 圈 PubMed 圈

2. Stetler CB, Mittman BS, Francis J. Overview of the VA Quality Enhancement Research Initiative (QUERI) and QUERI theme articles: QUERI Series. Implement Sci 2008;3:8. CrossRef \&ubMed 国

3. Dodson EA, Baker EA, Brownson RC. Use of evidence-based interventions in state health departments: a qualitative assessment of barriers and solutions. J Public Health Manag Pract 2010;16(6):E9-15. CrossRef 因 PubMed 圈

4. Hannon PA, Fernandez ME, Williams RS, Mullen PD, Escoffery C, Kreuter MW, et al. Cancer control planners' perceptions and use of evidence-based programs. J Public Health Manag Pract 2010;16(3):E1-8. CrossRef 圈 PubMed 国

5. Mascola AJ. Guided mentorship in evidence-based medicine for psychiatry: a pilot cohort study supporting a promising method of real-time clinical instruction. Acad Psychiatry 2008;32(6):475-83. CrossRef 因 PubMed 圈

6. Frei E, Stamm M, Buddeberg-Fischer B. Mentoring programs for medical students - a review of the PubMed literature 2000-2008. BMC Med Educ 2010;10:32. CrossRef 国 PubMed 圈

7. Lengerich EJ, Siedlecki JC, Brownson R, Aldrich TE, Hedberg K, Remington P, et al. Mentorship and competencies for applied chronic disease epidemiology. J Public Health Manag Pract 2003;9(4):275-83. CrossRef 因PubMed 圈

8. Alpert JBM. American Heart Association Mentoring Handbook. 2nd edition. Chicago (IL): American Heart Association; 2008.

9. Brownson RC, Fielding JE, Maylahn CM. Evidence-based public health: a fundamental concept for public health practice. Annu Rev Public Health 2009;30:175-201. CrossRef 国 PubMed 圈

10. Purcell EP, Mitchell C, Celestin MD, Evans KR, Haynes V, McFall A, et al. Research to reality (R2R) mentorship program: building partnership, capacity, and evidence. Health Promot Pract 2013;14(3):321-7. PubMed 圈

11. Jacobs JA, Jones E, Gabella BA, Spring B, Brownson RC. Tools for implementing an evidence-based approach in public health practice. Prev Chronic Dis 2012;9:E116. PubMed 圈

\section{Tables}

Table 1. Research to Reality Pilot Mentorship Program, Mentee Applicant and Mentee Characteristics, National Cancer Institute, 2011

\begin{tabular}{|c|c|c|}
\hline Applicant Characteristic & $\begin{array}{l}\text { All Applicants, No. (\%) }(n= \\
48)\end{array}$ & $\begin{array}{c}\text { Selected Mentees, No. }(\%)(n= \\
6)\end{array}$ \\
\hline \multicolumn{3}{|l|}{ Sex } \\
\hline Female & $42(88)$ & $5(83)$ \\
\hline Male & $6(13)$ & $1(17)$ \\
\hline \multicolumn{3}{|l|}{ Highest degree } \\
\hline Less than Bachelor's & $1(2)$ & - \\
\hline Bachelor degree & $6(13)$ & $2(33)$ \\
\hline Masters (non-public health) & $13(27)$ & $2(33)$ \\
\hline Masters (public health) & $23(48)$ & $2(33)$ \\
\hline $\mathrm{PhD}$ or $\mathrm{MD}$ & $5(10)$ & - \\
\hline \multicolumn{3}{|c|}{ Cancer Control Coalition experience } \\
\hline Yes, currently & $28(58)$ & $6(100)$ \\
\hline Yes, in the past & $3(6)$ & - \\
\hline No, never & $17(35)$ & - \\
\hline Organization typea & & \\
\hline
\end{tabular}




\begin{tabular}{|c|c|c|}
\hline Applicant Characteristic & $\begin{array}{l}\text { All Applicants, No. (\%) }(n= \\
48)\end{array}$ & $\begin{array}{c}\text { Selected Mentees, No. }(\%)(n= \\
6)\end{array}$ \\
\hline Academic & $9(19)$ & $2(33)$ \\
\hline Cancer center & $11(23)$ & $1(17)$ \\
\hline Clinical center & $10(21)$ & $1(17)$ \\
\hline Government & $6(13)$ & $2(33)$ \\
\hline State & $4(8)$ & $2(33)$ \\
\hline Local (county/tribal) & $2(4)$ & \\
\hline Other & $12(25)$ & - \\
\hline \multicolumn{3}{|c|}{ Portion of job that includes planning and/or implementing cancer control programs } \\
\hline All $(>95 \%)$ & $21(44)$ & $4(67)$ \\
\hline Most $(65 \%-95 \%)$ & $14(29)$ & $1(17)$ \\
\hline About half $(35 \%-64 \%)$ & $6(13)$ & $1(17)$ \\
\hline Some $(<35 \%)$ & $5(10)$ & - \\
\hline Don't know/Prefer not to answer & $2(4)$ & - \\
\hline \multicolumn{3}{|l|}{ Prioritized competenciesa } \\
\hline Advocacy and communication skills & $22(46)$ & $4(67)$ \\
\hline Assessment/analytic skills & $22(46)$ & $4(67)$ \\
\hline Basic public health science skills & $12(25)$ & - \\
\hline Cultural competency skills & $14(29)$ & $1(17)$ \\
\hline $\begin{array}{l}\text { Partnership, collaboration, and engagement } \\
\text { skills }\end{array}$ & $28(58)$ & $3(50)$ \\
\hline Policy development/program planning skills & $36(75)$ & $4(67)$ \\
\hline \multicolumn{3}{|l|}{ Project primary cancer topic } \\
\hline Breast cancer & $5(10)$ & - \\
\hline Cancer health disparities & $4(8)$ & - \\
\hline Cervical cancer & $2(4)$ & $1(17)$ \\
\hline Clinical trials accrual & $2(4)$ & - \\
\hline Colorectal cancer & $7(15)$ & $2(33)$ \\
\hline Obesity, diet/nutrition, physical activity & $4(8)$ & $1(17)$ \\
\hline Patient navigation & $3(6)$ & - \\
\hline Sun safety/skin cancer & $1(2)$ & $1(17)$ \\
\hline Survivorship & $9(19)$ & - \\
\hline Tobacco control & $4(8)$ & $1(17)$ \\
\hline Other & $7(15)$ & - \\
\hline
\end{tabular}

Abbreviation: -, no responses.

a Total may exceed $100 \%$ because applicants could give more than 1 response. 
Preventing Chronic Disease | Building Cancer Control Capacity: a Mixed-Method Evalua... Page 6 of 6

Table 2. Priority Competency Areas Selected by Mentees, Average Ratings on a 4-Point Scale of all Mentees at Program Completion, and Average Increase in Ratings From Program Initiation to Completion: Research to Reality Pilot Mentorship Program, National Cancer Institute, 2011

\begin{tabular}{|l|r|r|r|}
\hline Competency & \multicolumn{1}{|c|}{$\begin{array}{c}\text { No. of Mentees } \\
\text { Selecting This Area }\end{array}$} & $\begin{array}{c}\text { Average Rating at } \\
\text { Program Completiona }\end{array}$ & $\begin{array}{c}\text { Average Increase } \\
\text { in Ratings }\end{array}$ \\
\hline 1. Analytic/assessment & 4 & 3.0 & 0.8 \\
\hline $\begin{array}{l}\text { 2. Policy development/program } \\
\text { planning }\end{array}$ & 3 & 3.1 & 1.0 \\
\hline 3. Cultural competency & 1 & 3.1 & 0.2 \\
\hline 4. Public health science & 0 & 3.2 & 0.6 \\
\hline $\begin{array}{l}\text { 5. Partnership, collaboration, and } \\
\text { community engagement }\end{array}$ & 4 & 3.3 & 0.8 \\
\hline 6. Advocacy and communication & 4 & 2.7 & 0.4 \\
\hline
\end{tabular}

a Each competency was rated by participants on a 4-point scale ( $1=$ no ability, $4=$ expert $)$.

The opinions expressed by authors contributing to this journal do not necessarily reflect the opinions of the U.S. Department of Health and Human Services, the Public Health Service, the Centers for Disease Control and Prevention, or the authors' affiliated institutions.

The RIS file format is a text file containing bibliographic citations. These files are best suited for import into

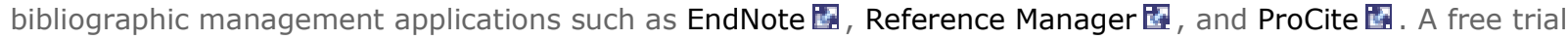
download is available at each application's web site.

For Questions About This Article Contact pcdeditor@cdc.gov

Page last reviewed: February 20, 2014

Page last updated: February 20, 2014

Content source: National Center for Chronic Disease Prevention and Health Promotion

Centers for Disease Control and Prevention 1600 Clifton Rd. Atlanta, GA 30333, USA

80o-CDC-INFO (800-232-4636) TTY: (888) 232-6348 - Contact CDC-INFO

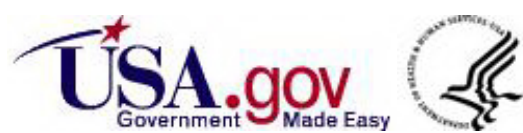

